The book is characterized by realistic appraisals of the value of various X-ray techniques. Although the General Electric Laboratory made major contributions to the field of X-ray absorptiometry, the authors stress that emission applications are far more important and consequently reduced the discussion on absorptiometry-a technique with important but limited applications. Probably the most valuable chapter to the practising analyst is the one on general sample preparation, remedies and compensations. In the recent advertisements by the X-ray instrument companies, particularly those extolling energy dispersive techniques, the reader is led to believe that all problems can be solved in seconds with a semiconductor detector and a dedicated computer. In spite of all the advances in instrumentation, the authors' summary statement is still appropriate, "In most cases sample preparation and not the spectrograph system, if functioning properly, will limit the reliability of results." This point cannot be overly emphasized if the analyst wishes to avoid large systematic errors for many types of samples.

The authors also convey to the reader the importance of weighing the merits and limitations of X-ray techniques with other competitive analytical techniques such as atomic absorption and optical emission. Both analysts and instrument manufacturers must be aware of new developments in analytical chemistry that compete with their speciality. A recent example is the virtual takeover of electron probe X-ray spectrography by scanning electron microscopes having $\mathrm{X}$-ray optical capability. The authors' paraphrase of the late President Truman is apropos in regard to X-ray methods, "If despite their manifest advantages they cannot withstand the heat of competition-they had better get out of the kitchen."

This new book is a welcome addition to the X-ray analyst's library and is recommended as a text for a course on $\mathrm{X}$-ray methods of analysis as it includes $\mathrm{X}$-ray diffraction and absorptiometry in addition to X-ray spectrography.

William J. Campbell

\section{Algae Revisited}

The Algae. By V. J. Chapman and D. J. Chapman. Pp. xiv +497. (Macmillan: London and Basingstoke, March 1973.) £6.95.

TEACHers of phycology have need of an accurate, up-to-date account of the algae for student use in courses on these important plants. This new edition of The Algae by V. J. and D. J. Chapman does not, unfortunately, fill that need.

The later chapters include useful short accounts of marine and freshwater algal ecology, with examples of different situations and different approaches to their study. The final chapter on algal physiology is so condensed that its usefulness is less certain, though it may serve as a lead-in to the research literature. In fact, with good reviews of algal ecology (Lewis, 1964; Round, 1965, for example), physiology and biochemistry (Stewart, 1973 for example) already available, what our students really need is a modern textbook on algal structure and reproduction, a latterday "Fritsch". It is precisely in this area that the book is less than satisfactory, with inaccuracies which vitiate its commendably wide coverage of organisms. (The advantage of this coverage is that students are more likely to find mention of an alga they are studying; the disadvantage is that the book tends to become a catalogue of thumb-nail sketches. In Structure and Reproduction of the Algae (1935, 1945), Fritsch took 1,750 closely packed pages to cover a wide range of plants and to include detailed accounts of the most important ones.)

In the taxonomic portion of the present book the annoying inaccuracies and imprecisions of language begin with the opening glossary and continue throughout the text. For example, in the glossary, the term "Frustule" is defined as "One half of a cell (Bacillariophyceae)", causing confusion with the main text (page 177), where the term is correctly given as synonymous with the total shell or wall of the diatom cell. Again, "Haptonema" is defined as "Flagella-like organ used for attachment to substrate (Haptophyceae)". Apart from problems over endings ("haptonema" is singular, "flagella" plural), this definition obscures the significant structural differences between haptonemata and flagella, and begs the question of haptonematal function, points also not adequately discussed in the text (page 172). Reading on, one is continually worried by similar inaccuracies, imprecise statements and misspellings (flaggelates, accomodated, Bourelly).

The arrangement of the taxonomic section is potentially confusing to students. There seems to be a desire to have chapters of about the same length, so that larger divisions (Chlorophyta, Phaeophyta, Rhodophyta) are arbitrarily split among several chapters, without uniform sub-headings, whereas smaller, not necessarily related, groups are put together (for example, chapter 6, Euglenophyta, Xanthophyta, Chloromonadophyta). Why not just have one chapter to each division? Incidentally, the page heading "Haptophyta" appears twice during the diatom section, when no such division is to be found in the book. Perhaps this is a subconscious feeling towards what I would have regarded as a correct decision to separate the Haptophyceae off from the
Chrysophyta as the division Haptophyta.

The Haptophyceae appear in this textbook for the first time in this edition, as do the Eustigmatophyceae, given as a class in the summary of classification at the beginning (page 7) but only as a paragraph within the Xanthophyceae in the main text (page 128). The important phycological reason for separating these last two classes, that motile cells of the former are unique in structure and less like those of the Xanthophyceae than the latter are like those of the Chrysophyceae and Phaeophyceae, is not mentioned. The other newcomers to this edition are the Euglenophyta, and minor inaccuracies and misconceptions again occur in the three pages devoted to them. The few drawings of euglenoids in this section are woefully inadequate and are not, as stated, "after Leedale". Three of the eight drawings are of "Colacium caluum" (misspelling for C. calvum, a species of doubtful validity) ; Fig. $6.1, g$, is described as " $C$. caluum, euglenoid zoospore attached", a phrase I am still trying to interpret.

Mention of these drawings brings me to the low standard of many of the illustrations. Examples of sketchy misrepresentation begin with the bluegreens (for example, Nostoc, Fig. 2.8, shown with cells of irregular shape and size) and continue through the other groups. Perhaps the most amazing feature, however, is the total absence of photographs. The algae have been a rich area of cytological and ultrastructural research during the past 20 years, providing results of fundamental importance in comparative phycology and in the wider regions of basic biological information. This is for the most part ignored in the present book, and where ultrastructural studies are mentioned (diatom locomotion, eyespot structure, haptophycean scales, and so on) the significance of the observations is not adequately discussed. It seems regrettable that a new edition of a textbook on the algae published in 1973 can still include no electron micrographs; it is surely inadequate to have a few drawings of micrographs (for example, Figs 3.4, 8.7) which lack both the accuracy and impact of the real thing.

The algae are exciting plants, of absorbing interest for their fascinating structure, their range of reproductive systems, the diversity of their life-cycles, their physiological and biochemical variety, and for what study of these features has to tell us about the evolution and functioning of biological systems. The present book represents a missed chance to produce a stimulating student text combining studies of the algae by modern techniques with classical studies on morphology and lifehistories.

Gordon F. LEEDALE 